\title{
Evaluation of Small-Scale Combustion of an Insensitive High Explosive formulation containing 3-nitro-1,2,4-triazol-5-one (NTO), 2,4-dinitroanisole (DNAN) and 1,3,5-trinitroperhydro-1,3,5-triazine (RDX)
}

\author{
Erick B F Galante ${ }^{1,2}$, Nathalie Mai ${ }^{1}$, Melissa Ladyman ${ }^{1}$, Philip P. Gill ${ }^{1}$, Tracey \\ Temple $^{1}$, Frederic Coulon ${ }^{1}$ \\ ${ }^{1}$ Centre for Defence Chemistry \\ Cranfield University \\ Defence Academy of the United Kingdom \\ Swindon, SN6 8LA, UK \\ ${ }^{2}$ IME - Instituto Militar de Engenharia, Brazilian Army, Brazil
}

\begin{abstract}
Energetic materials are often disposed by open-burning or open-detonation as it is a cost-effective and efficient means of destroying explosive material, and often minimises the need to transport hazardous explosives to treatment facilities. This practice is often scrutinised for the negative environmental impact of the odorous and unsightly toxic gaseous emissions as well as the resulting deposition residues, which often contain unburned energetic materials. With the increasing use of Insensitive High Explosive compositions in munitions, it is essential that the potential environmental impact of their disposal is assessed before their extensive use to prevent the kind of contamination incidents experienced with legacy explosives.
\end{abstract}

Therefore, the aim of this work was to develop a controlled laboratory experiment to identify the gaseous emissions and the energetic material residues that are generated through the combustion of the IHE components 3-nitro-1,2,4-triazol-5-one (NTO), 2,4-dinitroanisole (DNAN) and 1,3,5- 
trinitroperhydro-1,3,5-triazine (RDX). A sealed vial containing small (mg) quantities of energetic material was heated until the energetic material combusted. Gas chromatography/mass spectrometry (GCMS) was used to calculate the oxygen consumption and to identify the gases that were generated. The solid residues were analysed by high-performance liquid chromatography (HPLC) to quantify unburned energetic material.

Results showed that DNAN was the most resistant to burning, thus leaving significant quantities of unreacted starting material in the vial. An interesting observation for the IHE formulation was that DNAN also inhibited the combustion of NTO and RDX. The gases emitted during the open burning of IHE components and mixtures included $\mathrm{CO}, \mathrm{CO}_{2}$ and $\mathrm{N}_{2} \mathrm{O}$ as expected, but the proportions differed when the components and mixture were compared, reflecting the influence of DNAN on the burning behaviour.

From our data we concluded that open burning DNAN-based formulations is an environmentally unfavourable waste-management practice for the disposal of IHEs mainly due to generation of solid residues as well as unburnt DNAN.

Key words: Open-burning, combustion products, ICT Thermodynamic Code, explosives, environment 


\section{Introduction}

Open-burning is a common practice for the disposal of explosives and munitions at manufacturing facilities, training ranges and on operations (Duijm and Markert 2002). Open burning is burning of any matter in an unconfined environment, often in a concreted area, in raised cadges or specially designed burn pans, such that all emissions are emitted directly into the surrounding environment (Estrellan and Iino 2010). Ideally, the burn will be high temperature with access to an excess of oxygen leading to production of carbon dioxide, water and nitrous oxides. However, often open burning is inefficient, particularly in the lower temperature latter stages where toxic by-products are more likely to be produced (Krasnov and Fil'chakov 1996; Lemieux, Lutes, and Santoianni 2004; Thiboutot et al. 2019). Few reports have investigated the emissions and explosive residues produced during the open burning of IHE formulations. IHEs are known to deposit residual unreacted explosives on the soil after detonation, which suggests that explosive residues may also be deposited during open-burning (Clausen et al. 2004; Walsh, Walsh, and Ramsey 2012; Walsh, Walsh, and Hewitt 2010; Van-Ham 1991). The insensitive munitions explosive (IMX) series of IHE formulations use 2,4-dinitroanisole (DNAN) as the melt-castable binding agent for energetic materials such as 3-nitro-1,2,4triazol-5-one (NTO) and 1,3,5-trinitroperhydro-1,3,5-triazine (RDX), which in combination result in less sensitive compositions (Zunino 2012; S. Singh et al. 2010; Lee et al. 2010). These compounds are likely to be increasingly used to meet the need for insensitive munitions, however it is essential to determine whether disposal by open 
burning will increase the risk to the environment from the emission of toxic gasses, or the deposition of higher quantities of energetic material residues.

The impact of legacy energetic materials such as RDX on the environment has been well studied, and is supported by historic and ongoing environmental impacts such as RDX contamination in groundwater at manufacturing sites and training ranges (Clausen et al. 2004; Bannon and Williams 2015). The effects of NTO and DNAN are less well established, as is the effect of mixtures of RDX, NTO and though initial work suggests that once dissolved in the environment mixtures of IHE behave independently (Taylor et al. 2017; Temple et al. 2018). For DNAN based melt-cast formulations the dissolution rate is limited by the DNAN, which acts as a matrix for NTO and RDX (Morley et al. 2006). NTO is the most soluble of the three components, whereas RDX and DNAN are only sparingly soluble in water (Table 1) (Taylor et al. 2013).

In the environment, NTO quickly dissolves during periods of rainfall, leaving some DNAN and most of the RDX behind. However, RDX will dissolve over time and as it does not attenuate significantly to most soil types it tends to be mobile in soil environments and is likely to contaminate groundwater, as seen at several training ranges (Bordeleau et al. 2008; Pichtel 2012; Jenkins et al. 2006). DNAN and NTO are more likely to adsorb to soil and degrade, particularly in soils with high organic content (Arthur et al. 2017; Mark 2016). DNAN degradation products are in some cases more toxic than the parent compound, however the persistence and mobility of these degradation products requires further study (Dodard et al. 2013; J. Hawari et al. 2015). NTO has typically been found to show very little toxicity towards humans, however it is highly soluble and rapidly degrades in the environment most likely to 5-amino-1,2,4-triazol-3-one (ATO) and other 
degradation products. In addition, NTO is acidic (pKa 3.7-3.76) and may cause leaching of other contaminants such as heavy metals from soils, which is a particular concern at training ranges and demolition areas due where heavy metal contamination is common (Arthur et al. 2018; Clausen and Korte 2009). The environmental impact of NTO continues to be investigated, and the environmental impacts are not yet fully understood (Lent et al. 2012; Reddy et al. 2011; Jalal Hawari 2014). Due to the potential toxicity and mobility of energetic materials, explosives must therefore be disposed of responsibly, which is usually achieved by confined detonation, burning in a rotary kiln, open detonation (Shapira et al. 1978) or open burning (Tetra Tech 2002). The last two options are the most widely adopted methods in the military, although it is increasingly scrutinised and in some US states open burning activities require a permit (Aurell et al. 2015). In some cases, open burning and open detonation remains the safest method as it can be conducted in proximity to the munitions requiring disposal minimising transport and handling hazards. Open-burning or detonation must be conducted in a safe and secure environment and are the simplest and remain the least expensive techniques for the disposal of ammunition, missiles and explosives (Shyman and Ustimenko 2009). But despite the widespread use of these methods, the open detonation and open burning of energetic materials carries an environmental risk due to the deposition of unburnt residues from the explosive fillings and the production of gaseous emissions.

\section{Table 1. Toxicity and chemical properties of NTO, DNAN and RDX}

Much of the decomposition data available for energetic materials has been generated by conducting thermodegradation and thermostability tests, in many cases by differential scanning calorimetry (DSC) (Jimmie C. Oxley et al. 2016; Cuddy, Poda, and Chappell 
2014; Kim et al. 2016; T. B. Brill, Gongwer, and Williams 1994). Complementary thermal decomposition and combustion-like pyrolysis data have been provided using techniques such as controlled flash pyrolysis and the real-time detection of vaporized products by Fourier-transform infrared (FTIR) spectroscopy (Thomas B Brill, Arisawa, and Gongwer 1996). FITR has been used to analyse RDX following transient pyrolysis with a pulsed $\mathrm{CO}_{2}$ laser, revealing the scission of an $\mathrm{N}-\mathrm{N}$ bond leading to the formation of $\mathrm{N}_{2} \mathrm{O}_{4}$ (Botcher and Wight 1994). This experiment identified the origin of the nitrogen atoms in the $\mathrm{N}_{2} \mathrm{O}_{4}$ product and showed that $\mathrm{RDX}$ mainly produces $\mathrm{N}_{2} \mathrm{O}, \mathrm{H}_{2} \mathrm{O}, \mathrm{HCN}$, NO and $\mathrm{CH}_{2} \mathrm{O}$ during thermal decomposition. A similar technique was used to study NTO (J.C. Oxley et al. 1996). Following pyrolysis under low-oxygen conditions, the majority of the residual solids formed an insoluble condensed-phase brown product, whereas the gaseous decomposition products detected by gas chromatography/mass spectrometry (GCMS) comprised a mixture of $\mathrm{N}_{2}(43 \%), \mathrm{N}_{2} \mathrm{O}(6 \%), \mathrm{NO}(8 \%), \mathrm{CO}_{2}(37 \%)$ and $\mathrm{CO}$ (6\%). Moreover, NTO can sublimate and condensate during thermolysis (G. Singh and Srivastava 2015).

It may be expensive and time consuming to apply the techniques described above to some explosives, so computer simulations can be considered as an alternative. The ICT thermodynamic codes (Volk and Bathelt 1988; 1991a; 1991b) and ANSYS FLUENT (Kim et al. 2016; T. B. Brill, Gongwer, and Williams 1994) have both been used to model the behaviour of TNT, RDX and HMX. The ICT codes use mass action and mass balance expressions to calculate chemical equilibria. Thermodynamic equilibria can be calculated under constant pressure conditions or constant volume conditions, especially for the highpressure conditions of closed vessels and gun weapons. To achieve this output, when 
modelling mixed formulations, the ICT codes treat the mixture as a single component based on its empirical formula, thus disregarding further interactions between the individual ingredients.

To the best of our knowledge, none of the studies described above (experimental or computational) focused primarily on the gaseous emissions generated during the decomposition of explosives. Moreover, to fully assess and identify residues and emissions derived from IHEs apparatus that can achieve mass balance is required, so a closed-chamber, laboratory-scale method is ideal. For non-explosive fires there are some laboratory-scale methods available (BSI British Standard 2012; 2002; 2011; Association Francaise de Normalisation 2006; British Standard Institution 2016) to generate emission gases for analysis (particularly by GCMS), to determine their chemical composition.

In the context of explosives, Mitchell and Suggs (Mitchell and Suggs 1998) assessed the open burning and open detonation of mainly TNT $(\sim 2.2 \mathrm{~kg})$ using a $930 \mathrm{~m}^{3}$ container (described as a BangBox) comprising stainless-steel burn pans placed on a concrete pad located at the centre of the test chamber. They deployed sensors for the detection of $\mathrm{CO}$, $\mathrm{CO}_{2}, \mathrm{NO}, \mathrm{NO}_{2}, \mathrm{O}_{2}$ and $\mathrm{HCl}$, as well as canisters for measuring volatile organic compounds (VOCs). The gases trapped using the canister were analysed for total nonmethane hydrocarbons using two techniques: gas chromatography/flame ionization detection (GC/FID) and GCMS. The composited filters were extracted using the Soxhlet method prior to GCMS analysis. However, insufficient data are available for the implementation of an environmentally-friendly waste management plan for such 
materials, and for the development of procedures that ensure the effective disposal of IHE formulations, which are known to leave unreacted explosives in the soil even after the detonation of ordnance and munitions (Clausen et al. 2004; Walsh, Walsh, and Ramsey 2012; Walsh, Walsh, and Hewitt 2010; Van-Ham 1991).

The aim of this work was to identify the chemical signatures of the gases and vapours formed during combustion of Insensitive High Explosive (IHE) formulations, and to characterize the remaining residues. Here we describe a small-scale controlled laboratory method for assessing the behaviour of IHE materials when heated to combustion to determine the volume of remaining oxygen and identify decomposition gases, by GCMS. The solid residues were characterized for unburned energetic material by highperformance liquid chromatography (HPLC). This allowed us to investigate the combustion efficiency of an IHE formulation containing NTO, RDX and DNAN to gain insight into the impact of open burning methods when applied to these materials.

\section{Materials and Methods}

\section{Chemicals}

NTO (Chemring Nobel AS 2013) was manufactured in-house following a patented synthesis method (Primus, Goldenberg, and Hills 1988). DNAN (Sigma-Aldrich 2012) was purchased from Alfa Aesar (Thermo_Fisher 2018), whereas both RDX (Gjersøe 2011) and the IHE formulation (described hereafter as Formulation 1) were already available at Cranfield University. Table 2 presents the oxygen balance (Cooper 1996; Meyer et al. 2007), enthalpy of formation and other relevant characteristics of our test 
samples. Acetonitrile was purchased from Sigma-Aldrich and ultra-pure water was obtained from Merck-Millipore.

Table 2. Chemical properties of the explosive materials

\author{
(1) Calculated from the empirical formula \\ (2) Calculated from the enthalpy of formation of NTO, RDX and NTO
}

\title{
Method
}

The experimental setup (Figure 1) consisted of a sealed $10 \mathrm{~cm}^{3}$ Chromacol 10-CV-P715 GC headspace vial containing small samples $(10-20 \mathrm{mg})$ of the selected energetic material. The vial was placed on a custom-made aluminium block $(50 \times 50$ x $10 \mathrm{~mm})$ with a 2-mm thermocouple slot drilled from the edge to the centre and a $5 \mathrm{~mm}$ central groove for the headspace vial. A calibrated thermocouple was attached, and the apparatus was placed on a tripod. The heat source was a hand-held PT-200 butane blowtorch. The temperature data were collected using a Pico data logger USB TC-08 attached to an IECKX-2 thermocouple and the data were recorded using PicoLog Recorder software v5.25.3 (Pico Technology Limited 2016) at a rate of one measurement per second. The reported results are the average of 25 replicates. 
Figure 1. Schematic illustration of the experimental setup for the closed-vial combustion tests

To determine whether the septum contaminated the samples during heating, experimental trials were conducted using four types of Chromacol septum (20-CB3-510, 20-ACCBT3-719, 20-ST3HT-610 and 20-CBT30). None of the septa contaminated or interfered with the gaseous analysis, probably due to the short duration of each experiment (the heating phase was less than 6 min). Septum 20-CB3 510 showed evidence of mechanical deformation due to the increase in pressure within the headspace vial, whereas the other three septa were unaffected. Septum 20-ST3HT-610 was selected for the subsequent tests based on the manufacturer's recommendations regarding high-temperature experiments. An aluminium KIMBLE chromatography 73822A-20 20-mm seal was used to crimp each headspace vial. For each experiment, the temperature gradient was recorded and values for the first 100 samples gave an average rate of $43 \pm 1{ }^{\circ} \mathrm{C} \mathrm{min}^{-1}$.

\section{Analysis}

The initial materials were tested by DSC, and after burning the gaseous products were analysed by GCMS. Finally the solid residues were analysed and the explosive residues were quantified by HPLC.

High-performance liquid chromatography 
The solid residues were dissolved in $10 \mathrm{~cm}^{3}$ acetonitrile, passed through a $0.24-\mu \mathrm{m}$ Nylon Fishedbrand syringe filter and analysed using a Waters-Alliance 2695 HPLC system connected to a Waters-Alliance 996 photodiode array detector. The samples were fractionated on an analytical Waters NovaPak C8 column $(150 \mathrm{~mm} \times 3.9 \mathrm{~mm}, 4 \mu \mathrm{m}$ particle size) maintained at $30^{\circ} \mathrm{C}$. The mobile phase was 40:60:0.1 (v/v/v) acetonitrile/water/formic acid with a flow rate of $1.5 \mathrm{~mL} \mathrm{~min}^{-1}$. The injection volume was $10 \mu \mathrm{L}$ and the output signals were analysed at $296 \mathrm{~nm}$ for DNAN, $264 \mathrm{~nm}$ for RDX and $315 \mathrm{~nm}$ for NTO. To quantify each substance, a calibration curve was generated by plotting peak area versus the mass of the explosives injected. The HPLC was calibrated for each explosive from $10-50 \mathrm{ppm}$ through six calibration points.

\section{Differential scanning calorimetry}

The materials were thermally characterized using a Mettler Toledo LF1100 TGA/DSC 3+, equipped with a DSC sensor controlled by Stare System software v15.00 (build 8992). The samples were placed in a $40 \mu \mathrm{L}$ aluminium pierced crucible. The tests were conducted under an inert atmosphere $\left(\mathrm{N}_{2}\right.$ flowing at $\left.50 \mathrm{~cm}^{3} \mathrm{~min}^{-1}\right)$ and at two heating rates: 10 and $40{ }^{\circ} \mathrm{C} \min ^{-1}$.

\section{Gas chromatography/mass spectrometry}

Following the burning phase, the sample was left to cool down (for no more than $12 \mathrm{~h}$ ) and the gaseous content of the vial was characterized by GCMS using an Agilent Technologies 7890B GC system coupled to an Agilent Technology 5977A MSD. The 
GCMS system was controlled using Agilent Chemstation software. For chromatography, the initial temperature was set to $-80{ }^{\circ} \mathrm{C}$ for $1 \mathrm{~min}$, followed by a heating rate of $60{ }^{\circ} \mathrm{C} \mathrm{min}-1$ until the temperature reached $150{ }^{\circ} \mathrm{C}$, and then a 5 min heating period after the sample was injected into the Agilent ParaPlot Capillary Column (25 m length, $0.25 \mathrm{~mm}$ internal diameter and $8 \mu \mathrm{m}$ film thickness) with a flow of helium at $1.2 \mathrm{~cm}^{3} \mathrm{~min}^{-}$

1. The split ratio was 50:1 and the injection volume was $100 \mu \mathrm{L}$. The mass spectrometer (EI mode) set at $70 \mathrm{eV}$ ran in full-scan mode from 10 to $100 \mathrm{~m} / \mathrm{z}$. The GCMS data are reported in terms of relative percentage composition.

\section{Thermodynamic calculations}

The gases detected by GCMS were compared to simulated results obtained using the ICT Thermodynamic Code (Koch, Weiser, and Webb 2009; Volk and Bathelt 1988; 1991a) (Windows Fronted, v1.00) and the Database of Thermochemical Values. The simulations were carried out using the explosive formulation alone (to represent a detonation) and also with $20 \%$ (w/w) oxygen added to the formulation (to represent open burning). This figure was calculated by converting the volume of oxygen within the vial into mass, which was added to the explosive sample.

\section{Results and discussion}

Although open burning is the most widely used method to dispose of explosives, it is not suitable for the assessment of burning efficiencies because it does not preserve the reaction products or the mass balance. We therefore developed a laboratory-scale closed- 
chamber system to impose a heat flow that simulates the open burning of explosive samples. Under these conditions, we found that RDX underwent a violent reaction once vaporization was complete, breaching the vial seal and making it challenging to capture the gaseous emissions. Because RDX showed no reaction until $280^{\circ} \mathrm{C}$ was reached, its heating cycle was interrupted at $270{ }^{\circ} \mathrm{C}$ (to preserve the sample by avoiding violent reactions), allowing the residual heat to safely warm the sample until it reached $280{ }^{\circ} \mathrm{C}$. Even in this short test, we observed RDX evaporating and decomposing, but we believe the decomposition mechanism could be closer to pyrolysis than full burning. Table 3 lists the maximum temperature recorded for each compound before ignition was observed. The values are higher than the decomposition temperature available in the literature, which reflects a thermal lag introduced by our setup: we recorded the temperature in the aluminium base, which is hotter than the explosive itself.

Table 3. Temperatures of combustion observed during the closed heating of IHE components

The main purpose of open burning is to convert energetic and meta-stable chemicals (explosives) into more stable and less energetic forms such as $\mathrm{CO}_{2}$ and $\mathrm{H}_{2} \mathrm{O}$, ideally leaving no explosive materials among the solid residues. Our experimental setup achieved a full mass balance for both solid residues and gaseous emissions. When we tested the pure components, we found that $\sim 75 \%$ (w/w) of the DNAN remained unreacted after burning, whereas only $1-2 \%(\mathrm{w} / \mathrm{w})$ of the NTO and RDX were unburnt. When the same 
test was conducted on Formulation 1 (Figure 2) the solid residues were in the order of $\sim 23 \%$. For Formulation 1, DNAN not only showed resistance to burning, but was also able to draw heat from the system, increasing the amount of unburnt NTO and RDX residues.

Figure 2. Percentage of unburnt explosives remaining after combustion determined by HPLC - RDX/NTO/DNAN (individually and combined as Formulation 1)

DNAN was the most volatile of the three substances we tested (Cuddy, Poda, and Chappell 2014). Recent decomposition tests revealed evidence of decomposition at 200$300{ }^{\circ} \mathrm{C}$ after 5 days of continuous heating (Jimmie C. Oxley et al. 2016). Our data support the hypothesis that DNAN sublimes, drawing energy from the system and reducing the energy available for ignition of NTO and RDX thus increasing the quantity of residual solids. This behaviour was supported by thermo-characterization experiments, which showed no significant differences by heating rates of $10-40{ }^{\circ} \mathrm{C} \min ^{-1}$ (Figure 3). Under an inert atmosphere, NTO melted at $\sim 280{ }^{\circ} \mathrm{C}\left(278{ }^{\circ} \mathrm{C}\right.$ at $10{ }^{\circ} \mathrm{C}$ min- 1 heating rate and 282 ${ }^{\circ} \mathrm{C}$ at $40{ }^{\circ} \mathrm{C}$ min-1 heating rate), whereas Formulation 1 melted at $220-260{ }^{\circ} \mathrm{C}$ when heated at the slower rate and at $220-280{ }^{\circ} \mathrm{C}$ when heated at the faster rate. DNAN was able to undergo both sublimation, melting and evaporation. It melted at $\sim 100{ }^{\circ} \mathrm{C}$ at both heating rates $\left(98{ }^{\circ} \mathrm{C}\right.$ at the slowest heating rate and $101{ }^{\circ} \mathrm{C}$ at the fastest heating rate), but it evaporated at $280{ }^{\circ} \mathrm{C}$ when heated at $10{ }^{\circ} \mathrm{C}$ min- 1 and at $320^{\circ} \mathrm{C}$ when heated at $40{ }^{\circ} \mathrm{C}$ min-1. NTO melted at $280{ }^{\circ} \mathrm{C}\left(278{ }^{\circ} \mathrm{C}\right.$ at $10{ }^{\circ} \mathrm{C} \mathrm{min}{ }^{-1}$ heating rate and $282{ }^{\circ} \mathrm{C}$ at $40{ }^{\circ} \mathrm{C} \mathrm{min}{ }^{-1}$ heating rate), whereas Formulation 1 melted at $220-260{ }^{\circ} \mathrm{C}$ when heated at the slower rate and at $220-280{ }^{\circ} \mathrm{C}$ when heated at the faster rate. DNAN was able to undergo both melting and evaporation. It melted at $\sim 100^{\circ} \mathrm{C}$ at both heating rates $\left(\sim 98^{\circ} \mathrm{C}\right.$ 
at the slowest heating rate and $101{ }^{\circ} \mathrm{C}$ at the fastest heating rate) but it evaporated at $280{ }^{\circ} \mathrm{C}$ when heated at $10{ }^{\circ} \mathrm{C} \min ^{-1}$ and at $320{ }^{\circ} \mathrm{C}$ when heated at $40{ }^{\circ} \mathrm{C} \mathrm{min}-1$. These experiments were used to specify the maximum temperature for burning in the headspace vials. Moreover, DNAN sublimed without melting, whereas the DSC data indicated melting, which we believe is due to the temperature gradient present in the experimental setup.

Figure 3. Thermogravimetric analysis and differential scanning calorimetry results showing that DNAN sublimes before reaching a sufficient temperature for combustion (average results of three replicates)

The experiments described above indicate that, during open burning, DNAN does not burn completely but becomes a vapour and is transported in an unreacted state away from the burning area. Ultimately, this would spread contamination caused by unreacted explosives across a wider area, defeating the purpose of open burning.

As well as investigating the solid residues, we also assessed the gaseous emissions in the headspace vial. Initially we sought to determine whether the vial contains sufficiently oxygen-rich air atmosphere for our samples. There was a direct correlation between the oxygen balance of the explosives and the oxygen available/used in the vial. Figure 4 shows the relationship between oxygen available/used during combustion within the vial. Both RDX and NTO underwent a prompt combustion and consumed less oxygen than was available, because there was excess oxygen available for the stoichiometric combustion. DNAN and Formulation 1 used all of the available oxygen within the vial because they didn't have enough oxygen available for stoichiometric combustion. The majority of the DNAN in both experiments underwent a phase transition, partially 
subliming, partially melting and evaporating, and moved to the top of the vial instead of burning. The temperature gradient present in the experimental setup favoured the sublimation of DNAN followed by its solidification on the upper parts of the vial, remaining in an unreacted state.

Overall, the data indicated that burning a mixture containing DNAN is less efficient than burning pure RDX and/or NTO, which leaves more solid residues, increasing the potential environmental impact. Interestingly, NTO is known to undergo sublimation (J.C. Oxley et al. 1996; G. Singh and Srivastava 2015), but the heat flow provided by the experiment was sufficient to achieve its ignition temperature. In summary, the oxygen consumption of RDX, NTO, DNAN and Formulation 1 followed the same pattern as observed for the oxygen balance: the more oxygen-deficient the explosive, the more explosive residue is left in the vial post combustion.

\section{Figure 4. Comparison between oxygen used during combustion and available oxygen} within vial. Expressed as percentage oxygen for stoichiometric combustion.

The analysis of other gaseous products in the headspace vial (Figure 5) revealed that $\mathrm{N}_{2}$ levels increased above background for all samples, and water was also detected. The burning of RDX and NTO (together they represent $80 \%$ of Formulation 1) is responsible for producing the $\mathrm{CO}_{2}$ observed during the burning of Formulation 1. NTO makes up $\sim 50 \%$ of Formulation 1, and although it is more insensitive than RDX, it nevertheless plays an important role in producing this gas. Our solid residue analysis indicated that not all the raw materials burnt evenly, but across all the samples less $\mathrm{CO}$ than $\mathrm{CO}_{2}$ was 
produced. This confirms that $\mathrm{O}_{2}$ from the air plays a significant role in the burning reaction, thus indicating that our samples underwent combustion instead of pyrolysis or thermal decomposition.

\section{Figure 5. Combustion products observed when burning RDX/NTO/DNAN (individually} and combined) in a $10 \mathrm{~cm}^{3}$ headspace vial

As expected from previous studies (Botcher and Wight 1994), RDX produced the highest levels of $\mathrm{N}_{2} \mathrm{O}$ as an intermediary product (Botcher and Wight 1994), before forming other species such as $\mathrm{H}_{2} \mathrm{O}, \mathrm{HCN}$ and $\mathrm{NO}$, all of which were detected in our experiment. NTO produced the same qualitative gaseous emission mix as detected in an earlier pyrolysis experiment (J.C. Oxley et al. 1996), but the amount of $\mathrm{CO}_{2}$ was much higher (54\%) in our study compared to the previous study (37\%). Similarly, the amount of $\mathrm{N}_{2} \mathrm{O}$ increased from $6 \%$ in the pyrolysis study to $16 \%$ in our tests, which reinforces our conclusion that oxygen from the air plays a significant role in the gaseous emissions generated by NTO. Moreover, the gaseous products released by NTO, combined with the HPLC analysis of the solid residues, indicated a chemical reaction instead of phase transitions (sublimation and condensation) as observed in previous thermolysis tests (G. Singh and Srivastava 2015).

DNAN produced the lowest levels of $\mathrm{CO}, \mathrm{CO}_{2}$ and other chemical species, which is consistent with the poor efficiency of burning observed during the analysis of solid residues. $\mathrm{NO}_{2}$ was not analysed by GCMS due to the limitations of the column. Moreover, HCN has been detected in thermal decomposition studies of RDX and NTO, which suggests that DNAN produces HCN by thermal decomposition in our experiments. 
Unfortunately, it was not possible to investigate this phenomenon further using our experimental setup. The large amount of $\mathrm{N}_{2}$ reported for DNAN is due to the very low amount of gas generated - hence the $\mathrm{N}_{2}$ comes from the air.

The thermodynamic calculations (Figure 6) indicated that most of the nitrogen available in the sample would be converted into $\mathrm{N}_{2}$ (with trace amounts of $\mathrm{HCN}$ ). This is consistent with the oxygen-rich environment in the experiments compared to the low-oxygen environment assumed by the calculations. A key difference between the theoretical calculations and experiments was the $\mathrm{CO} / \mathrm{CO}_{2}$ ratio. The calculations predicted more $\mathrm{CO}$ than we observed, and again this is consistent with the assumed low-oxygen burning environment.

\section{Figure 6. Combustion products predicted when burning RDX/NTO/DNAN (individually and combined) as calculated using ICT codes, with and without added oxygen}

The data presented in Figure 6 compares the results from the ICT code (output measured in moles) against the empirical GCMS data, which refers to GC comparative peak areas. Although this could introduce a deviation factor for the concentrations and percentages, it does not compromise the results in terms of the chemical species observed and calculated.

When the ICT codes (Volk and Bathelt 1988; 1991a; 1991b) were used to predict the chemical species produced during burning, we observed compositional variation between the predicted and experimental results, which is likely to reflect the code design assumptions. The temperature gradient we applied was $\sim 43{ }^{\circ} \mathrm{C} \min ^{-1}$ up to $300{ }^{\circ} \mathrm{C}$, 
whereas the ICT code applies thermodynamic calculations for decomposition under constant pressure and a detonation temperature of $1500{ }^{\circ} \mathrm{C}$. Differences between the simulation and empirical results were also caused by the additional oxygen available in the experiments which was not automatically added by the ICT code, thus the user must introduce the required adjustments to match the amount of oxygen available under the experimental conditions. To compensate for the low-oxygen atmosphere in the calculations, we repeated the calculations adding $20 \%(\mathrm{w} / \mathrm{w})$ of oxygen into the mix, representing the amount of oxygen in air in the headspace vial and the average mass of explosive. When this adjustment was made, the simulation results for NTO and RDX moved closer to the experimental observations in the burning experiments. In the case of DNAN, the predicted gaseous products were completely different from those observed during the experiment, which supports our findings that DNAN is highly resistant to burning, undergoes melting and sublimation, and is transported away from the burning area. Our data adds to the body of evidence available for decomposition and stability studies focusing on RDX (Botcher and Wight 1994) and NTO (J.C. Oxley et al. 1996), although the samples in these earlier studies were heated for longer and were maintained under vacuum to determine their stability behaviour. In contrast, our study focused on the behaviour and potential environmental impact of IHE disposal by open burning.

As expected, the gases generated during the burning of Formulation 1 were not directly comparable to those produced by burning each pure component separately. This is likely to reflect the different oxygen balance in the mixture compared to each individual constituent (Genetier, Osmont, and Baudin 2014), and the combination of different thermal decomposition behaviours as indicated by DSC analysis. 
Given the volatility of DNAN and its positive heat of vaporization, it rapidly removes the heat generated when NTO and RDX are burning, reducing the available energy to sustain their combustion and rapidly moving away from the burning area while remaining unreacted. Therefore, although DNAN is less toxic than NTO and RDX, our work has shown that it is more resistant to burning and can leave more explosive residues after open burning, which may become an environmental hazard. Similarly, our results showed that the $\sim 23 \%$ residues of Formulation 1 left unreacted on the soil after open burning comprise $\sim 67 \%$ of the initial mass of DNAN and 13-20\% of the initial masses of NTO and RDX, which might become an environmental concern in the future. Robust and safe strategies for the disposal of DNAN (which is a fuel, not an explosive) must therefore be developed to avoid soil residues after detonation and open burning, and such methods should be made available before IHE rounds need to be decommissioned and disposed of in bulk.

\section{Conclusion}

The small-scale controlled method enabled identification of the gaseous and solid products of the decomposition of the selected IHE compositions. The thermodynamic calculations showed promising results when predicting the qualitative composition of gaseous emissions from RDX and NTO, as long as the available oxygen was taken into account. However, the simulation was less accurate when predicting the behaviour of DNAN. DNAN has a lower oxygen balance than RDX and NTO, meaning stoichiometric combustion was not possible within the vial. Additionally, DNAN sublimed, removing 
energy from the combustion reaction and increased the quantity of residues left behind. The replication of such behaviour in the field would defeat the purpose of open burning, because much of the explosive material would be left behind in an unreacted state. The experimental system described herein is constructed from inexpensive equipment but is versatile. In the future, it could be used to test the behaviour of IHEs and other novel formulations during burning, pyrolysis and heating cycles, providing much-needed insight into the behaviour of such materials in the environment. Finally, this work can be used to determine how to test and monitor the combustion behaviour of DNAN-based IHEs in small and medium scale open burning setups, which will provide insight into the environmental impact of emissions from the burning of IHEs in realistic military scenarios.

\section{Acknowledgements}

The authors would like to thank Dr Richard M. Twyman for his valuable comments and Clare Pratchett for the graphics and images. We also acknowledge the Centre for Defence Chemistry, Cranfield University, Shrivenham, and the Brazilian Army for supporting the work described in this manuscript. 


\section{References}

Arthur, Jennifer D., Noah W. Mark, Susan Taylor, J. Šimunek, M.L. Brusseau, and Katerina M. Dontsova. 2017. "Batch Soil Adsorption and Column Transport Studies of 2,4-Dinitroanisole (DNAN) in Soils." Journal of Contaminant Hydrology 199: 14-23. https://doi.org/10.1016/j.jconhyd.2017.02.004.

Arthur, Jennifer D., Noah W. Mark, Susan Taylor, Jiří Šimůnek, Mark L. Brusseau, and Katerina M. Dontsova. 2018. "Dissolution and Transport of Insensitive Munitions Formulations IMX-101 and IMX-104 in Saturated Soil Columns." Science of The Total Environment 624 (May): https://doi.org/10.1016/J.SCITOTENV.2017.11.307.

Association Francaise de Normalisation. 2006. NFX 70 100-1:2006 - Analysis of Pyrolysis and Combustion Gases. Tube Furnace Method. Part 1, Methods of Analysis of Gas Generated by Thermal Degradation. Part 2, Method of Thermal Degradation Using Tube Furnace. Association Francaise de Normalisation.

Aurell, Johanna, Brian K. Gullett, Dennis Tabor, Ryan K. Williams, William Mitchell, and Michael R. Kemme. 2015. "Aerostat-Based Sampling of Emissions from Open Burning and Open Detonation of Military Ordnance." Journal of Hazardous Materials 284 (March): 108-20. https://doi.org/10.1016/j.jhazmat.2014.10.029.

Bannon, Desmond I., and Lawrence R. Williams. 2015. "Wildlife Toxicity Assessment for 1,3,5-Trinitrohexahydro-1,3,5-Triazine (RDX)." In Wildlife Toxicity Assessments for Chemicals of Military Concern, edited by Marc. A. Williams, Gunda Reddy, J. Quinn, Michael, and S. Johnson, Mark, 53-86. Elsevier. https://doi.org/10.1016/B978-0-12-800020-5.00004-1.

Bordeleau, Geneviève, Richard Martel, Guy Ampleman, and Sonia Thiboutot. 2008. "Environmental Impacts of Training Activities at an Air Weapons Range." Journal of Environment Quality 37 (2): 308. https://doi.org/10.2134/jeq2007.0197.

Botcher, Tod R., and Charles a. Wight. 1994. "Explosive Thermal Decomposition Mechanism of RDX." The Journal of Physical Chemistry 98 (21): 5441-44. https://doi.org/10.1021/j100072a009.

Brill, T. B., P. E. Gongwer, and G. K. Williams. 1994. "Thermal Decomposition of Energetic Materials. 66. Kinetic Compensation Effects in HMX, RDX, and NTO." The Journal of Physical Chemistry 98 (47): 12242-47. https://doi.org/10.1021/j100098a020.

Brill, Thomas B, Haruyuki Arisawa, and Polly E Gongwer. 1996. "Combustion-like Pyrolysis of Organic Polymers: Species and Kinetic Details by T-Jump/FTIR Spectroscopy." In Symposium (International) on Combustion, edited by Anon, 1:791-98. Napoli, Italy: Combustion Inst, Pittsburg, PA, United States.

British Standard Institution. 2016. PD ISO/TS 19700:2016 Controlled Equivalence Ratio Method for the Determination of Hazardous Components of Fire Effluents. SteadyState Tube Furnace. British Standard Institution. 
BSI British Standard. 2002. ISO 5660-1:2002 Fire Tests - Reaction to Fire - Part 1: Rate of Heat Release from Building Products (Cone Calorimeter Method).

2011. ISO 12136:2011, Reaction to Fire Tests - Measurement of Material Properties Using a Fire Propagation Apparatus. 19.

- 2012. ISO 5659-2:2012 Plastics - Smoke Generation - Part 2: Determination of Optical Density by a Single-Chamber Test.

Chemring Nobel AS. 2013. "MSDS - Material Safety Data Sheet - NTO.” Norway.

Clausen, Jay, and Nic Korte. 2009. "The Distribution of Metals in Soils and Pore Water at Three U.S. Military Training Facilities." Soil and Sediment Contamination: An International Journal 18 (5): 546-63. https://doi.org/10.1080/15320380903085683.

Clausen, Jay, Joe Robb, Diane Curry, and Nic Korte. 2004. "A Case Study of Contaminants on Military Ranges: Camp Edwards, Massachusetts, USA." Environmental Pollution 129: 13-21. https://doi.org/10.1016/j.envpol.2003.10.002.

Cooper, Paul. 1996. Explosives Engineering. Edited by Wiley-Blackwell. 4th editio. New York, USA: Wiley-VCH, Inc. United States of America.

Cuddy, Michael F., Aimee R. Poda, and Mark A. Chappell. 2014. "Estimations of Vapor Pressures by Thermogravimetric Analysis of the Insensitive Munitions IMX-101, IMX-104, and Individual Components." Propellants, Explosives, Pyrotechnics 39 (2): 236-42. https://doi.org/10.1002/prep.201300069.

Dodard, Sabine G., Manon Sarrazin, Jalal Hawari, Louise Paquet, Guy Ampleman, Sonia Thiboutot, and Geoffrey I. Sunahara. 2013. "Ecotoxicological Assessment of a High Energetic and Insensitive Munitions Compound: 2,4-Dinitroanisole (DNAN)." Journal of Hazardous Materials 262 (November): 143-50. https://doi.org/10.1016/j.jhazmat.2013.08.043.

Duijm, Nijs Jan, and Frank Markert. 2002. “Assessment of Technologies for Disposing Explosive Waste." Journal of Hazardous Materials 90 (2): 137-53. https://doi.org/10.1016/S0304-3894(01)00358-2.

Estrellan, Carl Renan, and Fukuya Iino. 2010. "Toxic Emissions from Open Burning." Chemosphere. Pergamon. https://doi.org/10.1016/j.chemosphere.2010.03.057.

Genetier, M., A. Osmont, and G. Baudin. 2014. "Effect of the Oxygen Balance on Ignition and Detonation Properties of Liquid Explosive Mixtures." Journal of Physics: Conference Series $500 \quad$ (PART 19). https://doi.org/10.1088/17426596/500/19/192001.

Gjersøe, Richard. 2011. "MSDS - Material Safety Data Sheet - RDX.” Norway.

Hawari, J., F. Monteil-Rivera, N.N. N Perreault, A. Halasz, L. Paquet, Z. RadovicHrapovic, S. Deschamps, S. Thiboutot, and G. Ampleman. 2015. "Environmental Fate of 2,4-Dinitroanisole (DNAN) and Its Reduced Products." Chemosphere 119 (January): 16-23. https://doi.org/10.1016/j.chemosphere.2014.05.047.

Hawari, Jalal. 2014. "Environmental Fate and Ecological Impact of Emerging Energetic Chemicals (ADN, DNAN and Its Amino-Derivatives, PETN, NTO, NQ, FOX-7 and 
FOX-12) and an Insensitive Formulation." Vol. 3.

Jenkins, Thomas F., Alan D. Hewitt, Clarence L. Grant, Sonia Thiboutot, Guy Ampleman, Marianne E. Walsh, Thomas A. Ranney, Charles A. Ramsey, Antonio J. Palazzo, and Judith C. Pennington. 2006. "Identity and Distribution of Residues of Energetic Compounds at Army Live-Fire Training Ranges." Chemosphere 63 (8): 1280-90. https://doi.org/10.1016/j.chemosphere.2005.09.066.

Kim, Shin Hyuk, Baggie W. Nyande, Hyoun Soo Kim, Jung Su Park, Woo Jin Lee, and Min Oh. 2016. "Numerical Analysis of Thermal Decomposition for RDX, TNT, and Composition B." Journal of Hazardous Materials 308: 120-30. https://doi.org/10.1016/j.jhazmat.2015.12.061.

Koch, Ernst-Christian, Volker Weiser, and Rutger Webb. 2009. "Review on Thermochemical Codes." Bruxelles, Belgique.

Krasnov, V A, and A A Fil'chakov. 1996. "Composition of Combustion Products of Explosives and Their Mixtures." Combuistion, Explosion and Shock Waves 32 (6): 689-92.

Lee, K E, W A Balas-Hummers, A R Di Stasio, C H Patel, P J Samuels, B.D. Roos, and Virgil Fung. 2010. "Qualification Testing of the Insensitive TNT Replacement Explosive IMX-101." Insensitive Munitions and Energetic Materials Technology Symposium. New Jersey.

Lemieux, Paul M, Christopher C Lutes, and Dawn A Santoianni. 2004. "Emissions of Organic Air Toxics from Open Burning: A Comprehensive Review." Progress in Energy and Combustion Science $30 \quad$ (1): 1-32. http://www.sciencedirect.com/science/article/pii/S0360128503000613.

Lent, Emily May, Lee C B Crouse, Theresa Hanna, and Shannon Wallace. 2012. "The Subchronic Oral Toxicity of DNAN and NTO in Rats. Report: 87-XE-0DBP-10." US Army Institute of Public Health.

Mark, Noah W. 2016. "Batch and Column Transport Studies of Environmental Fate of 3Nitro-1 , 2 , 4-Triazol-5-One ( NTO ) in Soils.” The University of Arizona.

Meyer, Rudolph Rudolf, Josef Kohler, Axel Homburg, Josef Köhler, and Axel Homburg. 2007. Explosives. 6th, Compl ed. Weinheim: Wiley-VCH Verlag GmbH, Weinheim.

Mitchell, William, and Jack Suggs. 1998. "Emission Factors for the Disposal of Energetic Materials by Open Burning and Open Detonation (OB/OD) - EPA/600/R-98/103."

Morley, Matthew C., Hiroshi Yamamoto, Gerald E. Speitel, and Jay Clausen. 2006. "Dissolution Kinetics of High Explosives Particles in a Saturated Sandy Soil." Journal of Contaminant Hydrology $85 \quad$ (3-4): 141-58. https://doi.org/10.1016/j.jconhyd.2006.01.003.

Oxley, J.C., J.L. Smith, K.E. Yeager, E. Rogers, and X.X. Dong. 1996. "NTO Decomposition Studies." In Materials Research Society Symposium - Proceedings 418, 418:135-43. Pittsburgh, PA, United States: Materials Research Society,Pittsburgh, PA, United States. 
Oxley, Jimmie C., James L. Smith, Maria A. Donnelly, Kevin Colizza, and Stephanie Rayome. 2016. "Thermal Stability Studies Comparing IMX-101 (Dinitroanisole/Nitroguanidine/NTO) to Analogous Formulations Containing Dinitrotoluene." Propellants, Explosives, Pyrotechnics 41 (1): 98-113. https://doi.org/10.1002/prep.201500150.

Pichtel, John. 2012. "Distribution and Fate of Military Explosives and Propellants in Soil: A Review." Applied and Environmental Soil Science 2012: 1-33. https://doi.org/10.1155/2012/617236.

Pico Technology Limited. 2016. "PicoLog Recorder." England: Pico Technology Limited.

Primus, Frederick J, Milton D Goldenberg, and Short Hills. 1988. United States Patent US4733610 - 3-nitro-1,2,4-triazol-5-one, a less sensitive explosive. US4733610, issued 1988. https://doi.org/10.1016/j.(73).

Reddy, Gunda, Jian Song, Paul Kirby, Emily M. Lent, Lee C.B. Crouse, and Mark S. Johnson. 2011. "Genotoxicity Assessment of an Energetic Propellant Compound, 3Nitro-1,2,4-Triazol-5-One (NTO)." Mutation Research/Genetic Toxicology and Environmental Mutagenesis $\quad 719 \quad$ (1): https://doi.org/10.1016/j.mrgentox.2010.11.004.

Shapira, Norman I., James Patterson, John Brown, and Kenneth Noll. 1978. "EPA-600/278-012 - State of the Art Study: Demilitarization of Conventional Munitions." Cincinati, Ohio.

Shyman, L, and Y Ustimenko. 2009. "Disposal and Destruction Processes of Ammunition, Missiless and Explosives, Which Constitute Danger When Storing." NATO Science for Peace and Security Series A: Chemistry and Biology, 147-52. https://doi.org/10.1007/978-90-481-2342-1-19.

Sigma-Aldrich. 2012. "MSDS - Material Safety Data Sheet - DNAN." Dorset, United Kingdon.

Singh, Gurdip, and Pratibha Srivastava. 2015. "Thermal Decomposition of 5-Nitro-2, 4Dihydro-3H-1,2,4-Triazole-3-One (Nto) and Its Salts with Various Metals and Amines." In Recent Advances on Energetic Materials, edited by India) Gurdip Singh (Chemistry Department, DDU Gorakhpur University, Gorakhpur. Gorakhpur, India: Energy Science, Engineering and Technology.

Singh, Sanjeev, Lauren Jelinek, Philip Samuels, Anthony Di Stasio, and Leila Zunino. 2010. "IMX-104 Characterization for DoD Qualification." In 2010 Insensitive Munitions and Energetic Materials Technology Symposium. Munich, Germany, October. https://imemg.org/wp-content/uploads/IMEMTS 2010/papers/Singh10555_IMX-104 Qualification_IMEMTS2010-Paper.pdf.

Taylor, Susan, David B Ringelberg, Katerina Dontsova, Charles P Daghlian, Marianne E Walsh, and Michael R Walsh. 2013. "Insights into the Dissolution and the ThreeDimensional Structure of Insensitive Munitions Formulations." Chemosphere 93 (9): 1782-88. https://doi.org/10.1016/j.chemosphere.2013.06.011. 
Taylor, Susan, Marianne E. Walsh, Julie B. Becher, David B. Ringelberg, Philip Z. Mannes, and Gordon W. Gribble. 2017. "Photo-Degradation of 2,4-Dinitroanisole (DNAN): An Emerging Munitions Compound." Chemosphere 167: 193-203. https://doi.org/10.1016/j.chemosphere.2016.09.142.

Temple, T., M. Ladyman, N. Mai, E. Galante, M. Ricamora, R. Shirazi, and F. Coulon. 2018. "Investigation into the Environmental Fate of the Combined Insensitive High Explosive Constituents 2,4-Dinitroanisole (DNAN), 1-Nitroguanidine (NQ) and Nitrotriazolone (NTO) in Soil." Science of The Total Environment 625 (June): 126471. https://doi.org/10.1016/j.scitotenv.2017.12.264.

Tetra Tech. 2002. "Open Burning / Open Detonation Permitting Guidelines." Philadelphia, P.A.

Thermo_Fisher. 2018. “Alfa Aesar, Thermo Fisher Scientific.” 2018.

Thiboutot, S, R Martel, S Brochu, and Michael R Walsh. 2019. "Mitigation of the Environmental Footprint of a Munition." In Global Approaches to Environmental Management on Military Training Ranges, edited by T Temple and M Ladyman, 11-1-11-17. IOP Publishing. https://doi.org/10.1088/978-0-7503-1605-7ch11.

Van-Ham, N.H.A. 1991. "Environmentally Acceptable Disposal of Ammunition and Explosives." In 22nd International Annual Conference on ICT 1991, edited by Anon, 16.1-16.9. Karlsruhe, Ger: Internationale Jahrestagung - Fraunhofer-Institut fuer Treib-und Explosivstoffe.

Volk, F., and H. Bathelt. 1988. "User's Manual for the ICT-Thermodynamic Code / Vol. 1." ICT-Report 14/88. Pfinztal, Germany.

1991a. "User's Manual for the ICT-Thermodynamic Code / Vol. 2." ICT-Report 1/91. Pfinztal, Germany.

_. 1991b. "User's Manual for the ICT-Thermodynamic Code / Vol. 3." ICT-Report 2/91. Pfinztal, Germany.

Walsh, Michael R., Marianne E. Walsh, and Alan D. Hewitt. 2010. "Energetic Residues from Field Disposal of Gun Propellants.” Journal of Hazardous Materials 173 (13): 115-22. https://doi.org/10.1016/j.jhazmat.2009.08.056.

Walsh, Michael R, Marianne E Walsh, and Charles A Ramsey. 2012. "Measuring Energetic Contaminant Deposition Rates on Snow." Water Air Soil Pollut 223 (223): 3689-99. https://doi.org/10.1007/s11270-012-1141-5.

Zunino, Leila. 2012. "IMX-104 Characterization for DoD Qualification.” In Insensitive Munitions \& Energetic Materials Technology Symposium, 18. 


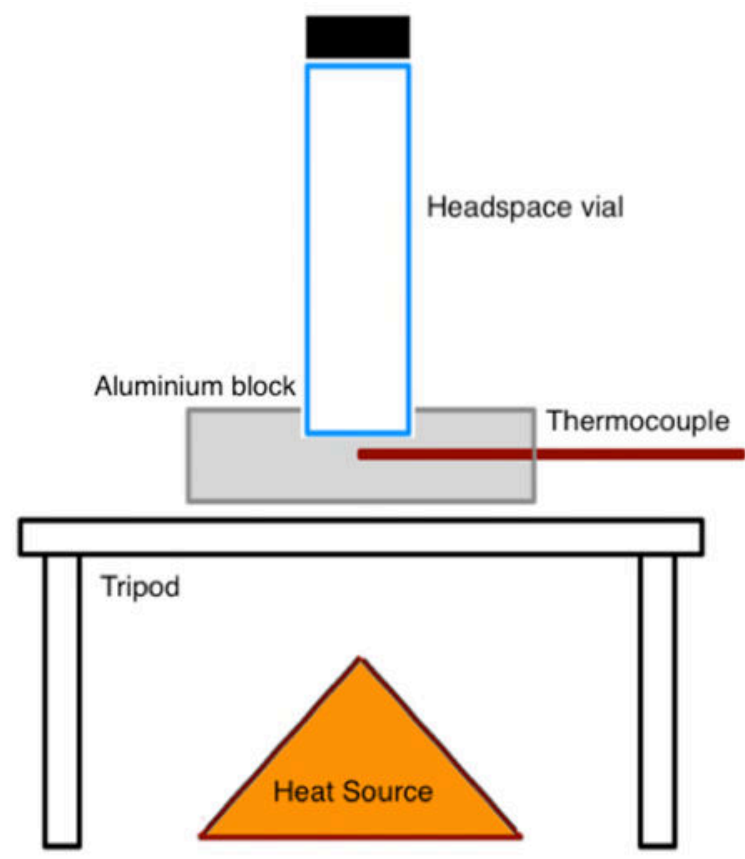

Figure 1. Schematic illustration of the experimental setup for the closed-vial combustion tests 

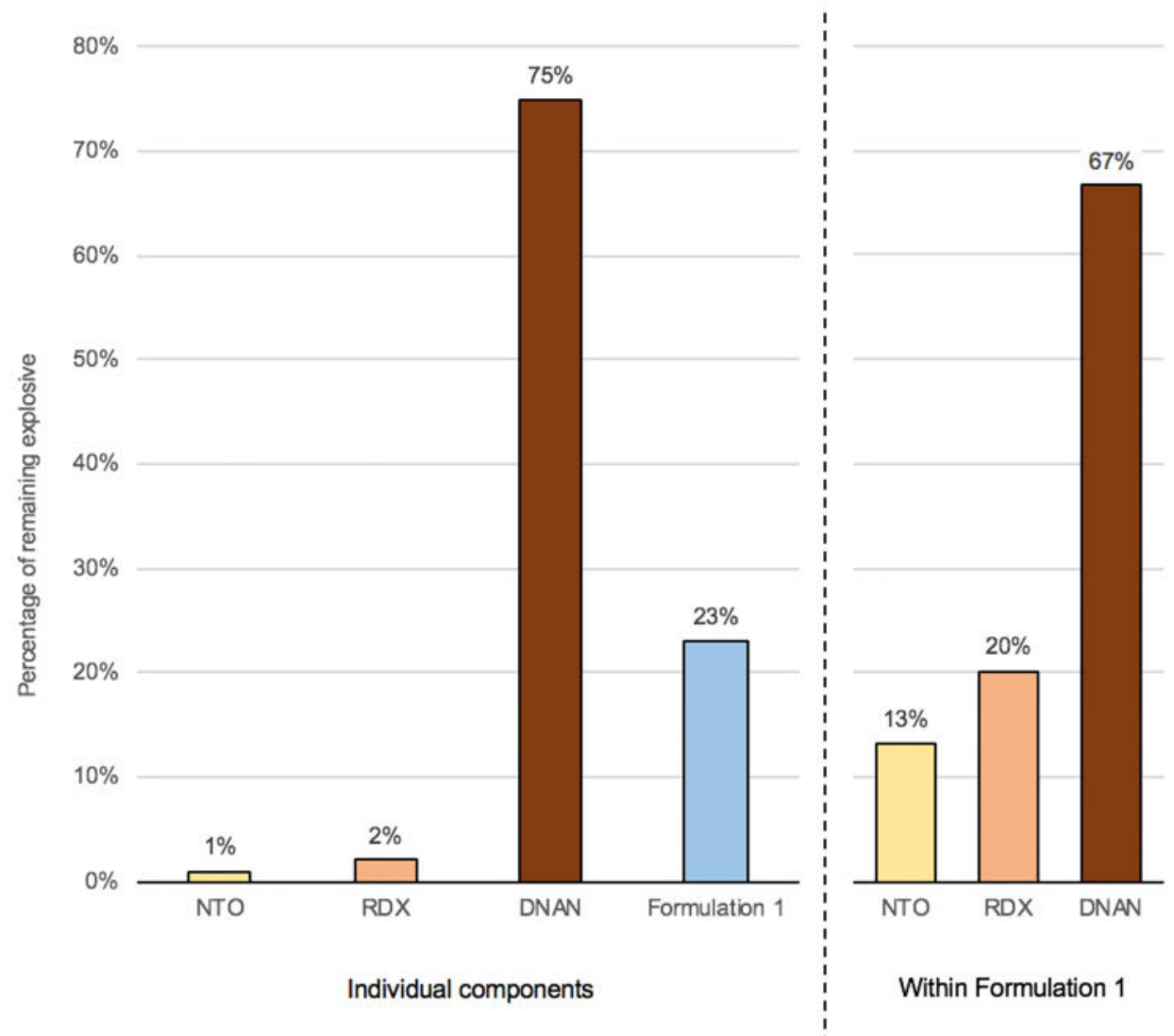

Figure 2. Percentage of unburnt explosives remaining after combustion determined by HPLC - RDX/NTO/DNAN (individually and combined as Formulation 1) 

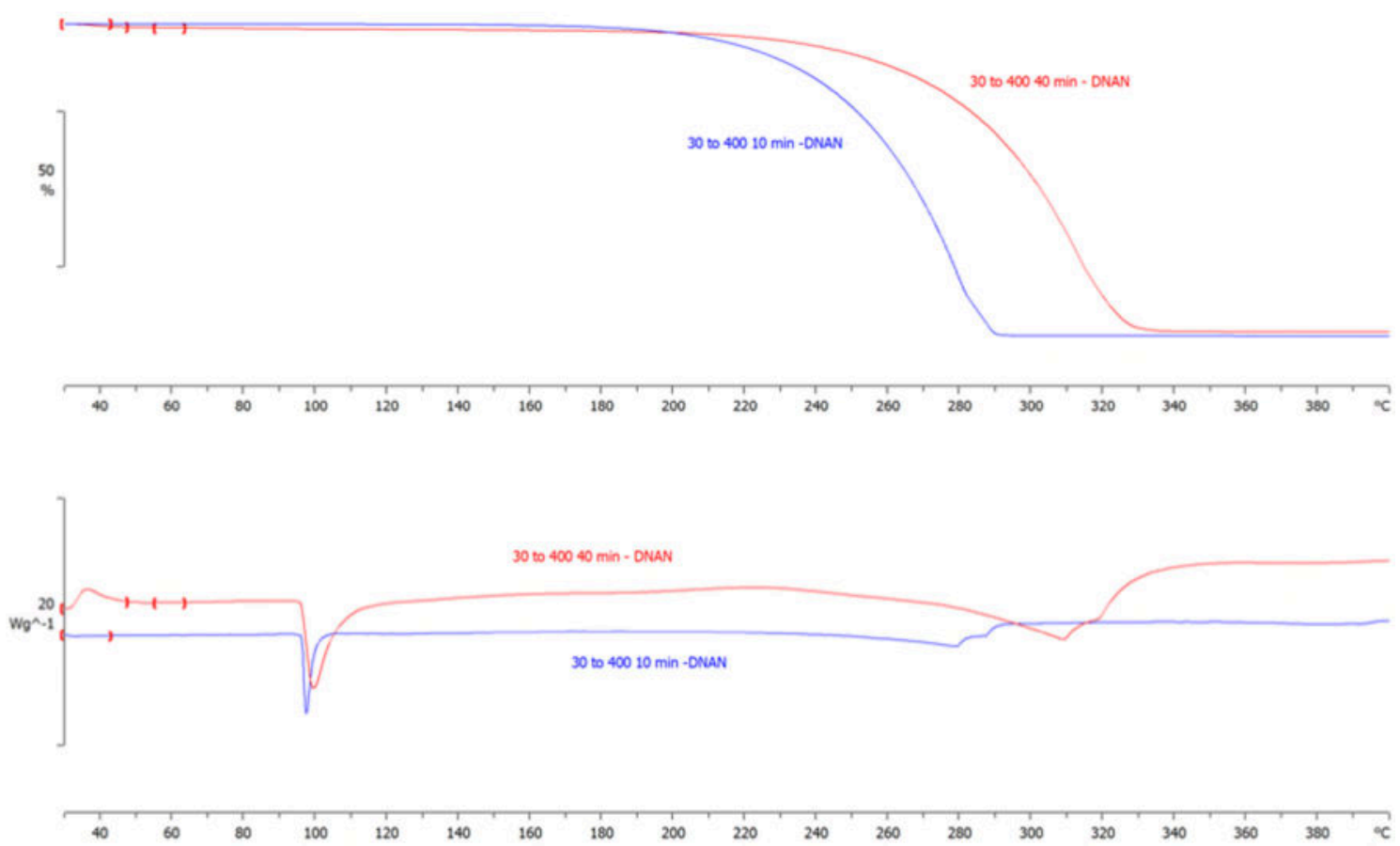

Figure 3. Thermogravimetric analysis and differential scanning calorimetry results showing that DNAN sublimes before reaching a sufficient temperature for combustion (average results of three replicates) 


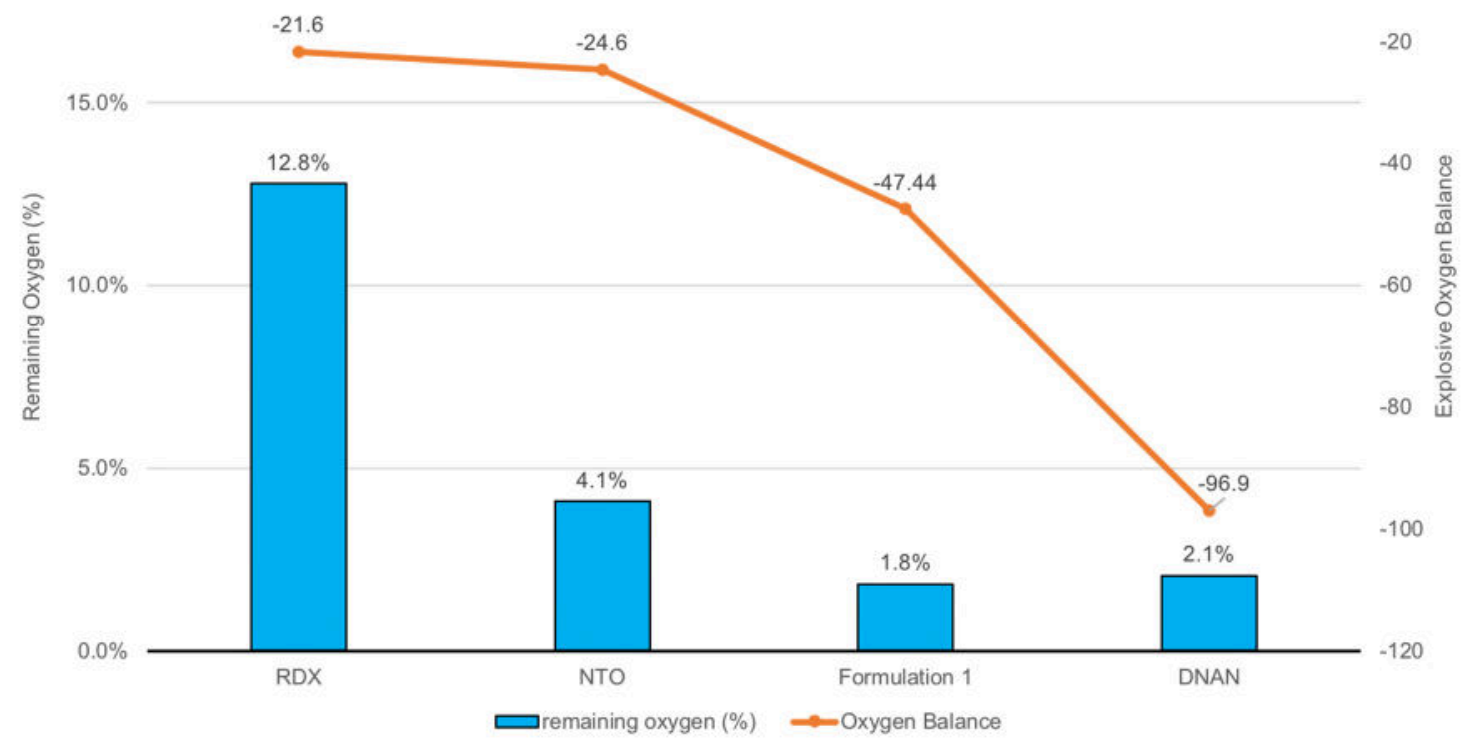

Figure 4. The oxygen balance of different explosives and mixtures compared to the oxygen remaining in the vial after combustion, the latter expressed as percentage of the initial concentration 


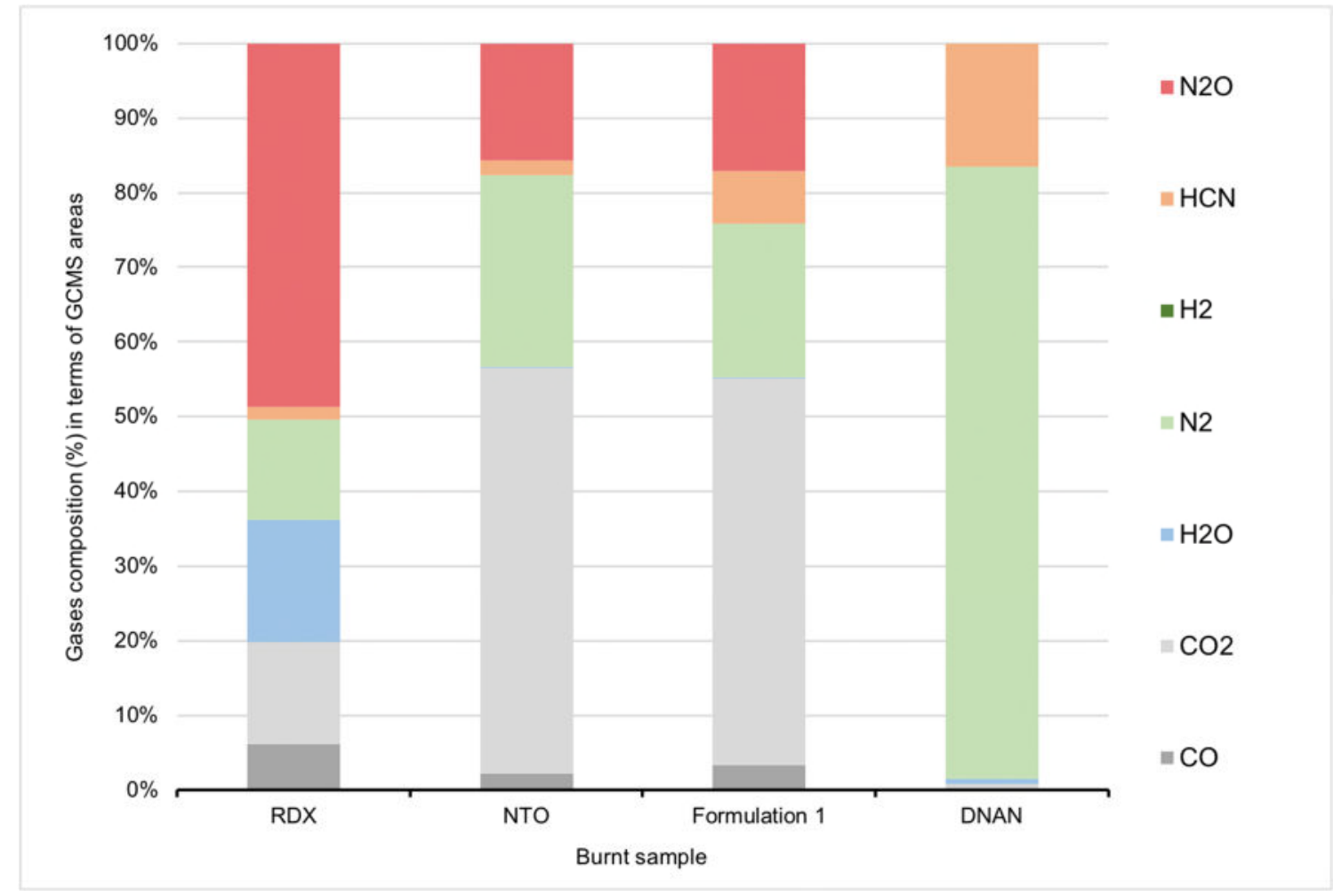

Figure 5. Combustion products observed when burning RDX/NTO/DNAN (individually and combined) in a $10 \mathrm{~cm}^{3}$ headspace vial 


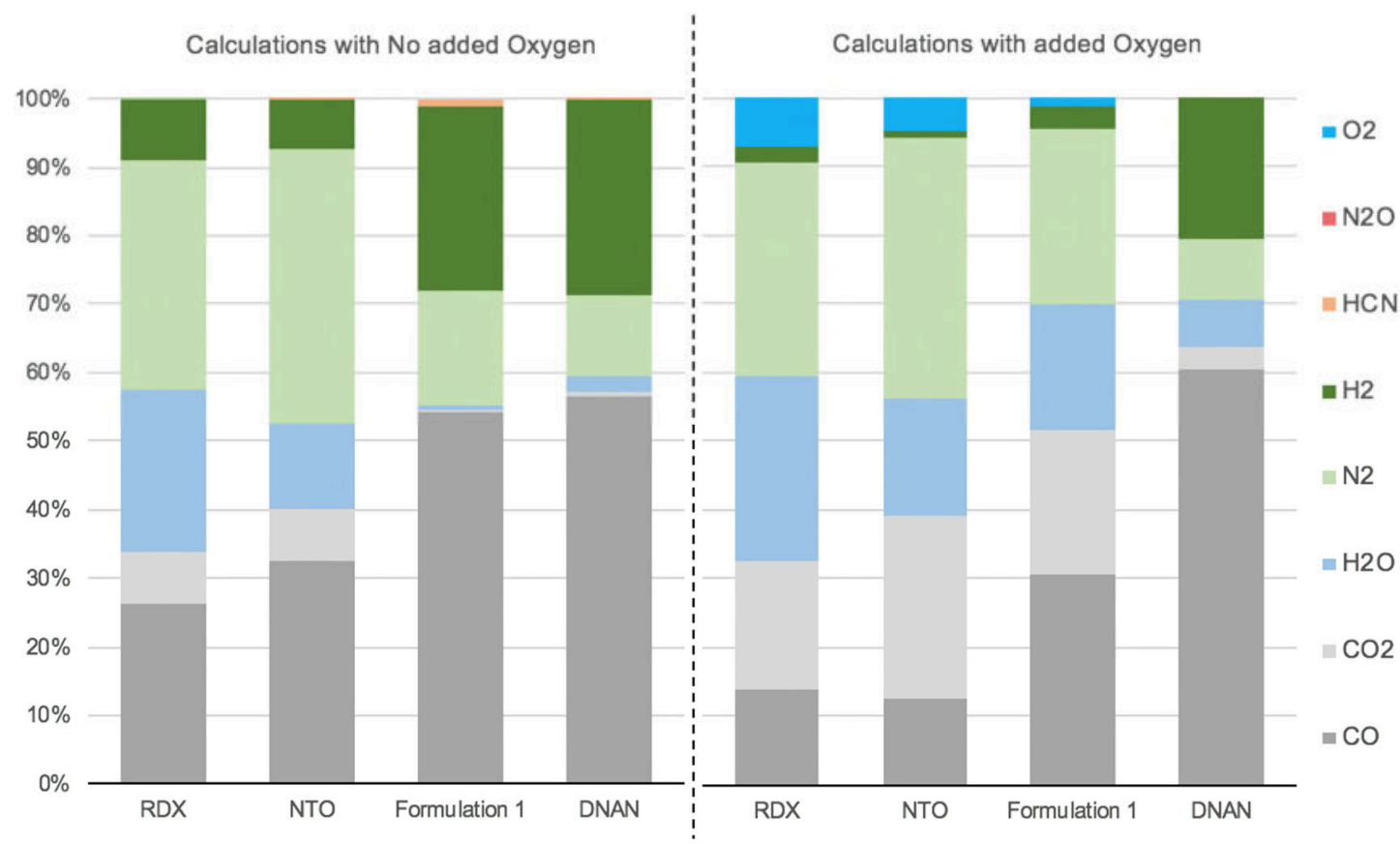

Figure 6. Combustion products predicted when burning RDX/NTO/DNAN (individually and combined) as calculated using ICT codes, with and without added oxygen

Table 1. Toxicity and chemical properties of NTO, DNAN and RDX

\begin{tabular}{|c|c|c|c|}
\hline Explosive & 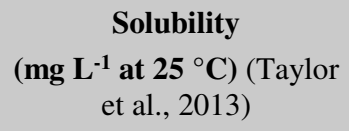 & $\begin{array}{l}\text { lethal dose (LD50) } \\
\left(\mathrm{mg} \mathrm{kg}^{-1} \text { in rats) }\right.\end{array}$ & 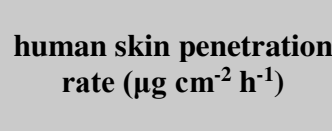 \\
\hline $\begin{array}{c}\text { NTO (Chemring Nobel } \\
\text { AS, 2013) }\end{array}$ & 16,642 & $\begin{array}{l}>5000 \text { (London and } \\
\text { Smith, 1985) }\end{array}$ & $\begin{array}{c}332 \text { (McCain, Williams } \\
\text { and Grunda, 2013) }\end{array}$ \\
\hline $\begin{array}{c}\text { DNAN (Sigma-Aldrich, } \\
\text { 2012) }\end{array}$ & 276 & $\begin{array}{c}300 \text { (Dodd and } \\
\text { McDougal, 2002; Lent et } \\
\text { al., 2012) }\end{array}$ & $\begin{array}{l}1.10 \text { (McCain, Williams } \\
\text { and Grunda, 2013) }\end{array}$ \\
\hline RDX (Gjersøe, 2011) & 60 & 100 (Meyer et al., 2005) & NA \\
\hline
\end{tabular}

Legend: NA - Not applicable

Table 2. Chemical properties of the explosive materials 


\begin{tabular}{|c|c|c|c|c|c|c|}
\hline Explosive & $\begin{array}{l}\text { Empirical } \\
\text { formula }\end{array}$ & $\begin{array}{l}\text { Chemical } \\
\text { structure }\end{array}$ & $\begin{array}{c}\text { Oxygen } \\
\text { balance } \\
(\%) \\
\text { (Cooper, } \\
1996 ; \\
\text { Meyer et } \\
\text { al., 2007) }\end{array}$ & $\begin{array}{c}\text { Melting } \\
\text { point } \\
\left({ }^{\circ} \mathrm{C}\right)\end{array}$ & $\begin{array}{l}\text { Decomposition } \\
\text { temperature }\left({ }^{\circ} \mathrm{C}\right)\end{array}$ & $\begin{array}{c}\begin{array}{c}\text { Enthalpy } \\
\text { of } \\
\text { formation }\end{array} \\
\Delta \mathbf{H}_{\mathrm{f}}{ }^{\circ} \text { solid } \\
\left(\mathrm{kJ} \mathrm{mol}^{-1}\right)\end{array}$ \\
\hline $\begin{array}{c}\text { NTO } \\
\text { (Chemring } \\
\text { Nobel AS, } \\
\text { 2013) }\end{array}$ & $\mathrm{C}_{2} \mathrm{H}_{2} \mathrm{~N}_{4} \mathrm{O}_{3}$ & & -24.60 & 270 & $270-273$ & -100.75 \\
\hline $\begin{array}{l}\text { DNAN } \\
\text { (Sigma- } \\
\text { Aldrich, } \\
\text { 2012) }\end{array}$ & $\mathrm{C}_{7} \mathrm{H}_{6} \mathrm{~N}_{2} \mathrm{O}_{5}$ & $\mathrm{NO}_{2}$ & -96.90 & $94-96$ & NA & -186.65 \\
\hline $\begin{array}{c}\text { RDX } \\
\text { (Gjersøe, } \\
\text { 2011) }\end{array}$ & $\mathrm{C}_{3} \mathrm{H}_{6} \mathrm{~N}_{6} \mathrm{O}_{6}$ & $\mathrm{NO}_{2}$ & -21.60 & 190 & $190-200$ & 66.94 \\
\hline Formulation 1 & $\mathrm{C}_{3.7} \mathrm{H}_{4} \mathrm{~N}_{3.8} \mathrm{O}_{4.2}$ & $\begin{array}{l}\text { NTO / DNAN / } \\
\text { RDX }\end{array}$ & $-47.44(1)$ & 90 & NA & $-107.8(2)$ \\
\hline
\end{tabular}

Legend: NA Not applicable

(1) Calculated from the empirical formula

(2) Calculated from the enthalpy of formation of NTO, RDX and NTO

Table 3. Temperatures of combustion observed during the closed heating of IHE components

\begin{tabular}{ccc}
\hline Compound & $\begin{array}{c}\text { Highest recorded temperature before } \\
\text { ignition was observed }\end{array}$ & Decomposition Temperature \\
\hline Formulation 1 & $300^{\circ} \mathrm{C}$ & $\mathrm{NA}$ \\
\hline NTO & $315^{\circ} \mathrm{C}$ & $270-273{ }^{\circ} \mathrm{C}$ \\
\hline RDX & $280{ }^{\circ} \mathrm{C}$ & $190-200{ }^{\circ} \mathrm{C}$ \\
\hline DNAN & $350^{\circ} \mathrm{C}$ & NA \\
\hline
\end{tabular}

